\section{Clastogenicity of Quinoline and Monofluorinated Quinolines in Chinese Hamster Lung Cells}

\author{
Takayoshi Suzuki, ${ }^{, a, b}$ Kenji Takeshita, ${ }^{a}$ \\ Ken-ichi Saeki, ${ }^{c}$ Minoru Kadoi, ${ }^{c}$ \\ Makoto Hayashi, ${ }^{a}$ and Toshio Sofuni ${ }^{a}$
}

\begin{abstract}
${ }^{a}$ Division of Genetics and Mutagenesis and ${ }^{b}$ Division of Cellular and Gene Therapy Products, National Institute of Health Sciences, 1-18-1 Kamiyoga, Setagaya-ku, Tokyo 158-8501, Japan, and ${ }^{c}$ Graduate School of Pharmaceutical Sciences, Nagoya City University, Tanabedori, Mizuho-ku, Nagoya 4678603, Japan
\end{abstract}

(Received October 5, 2006; Accepted March 12, 2007; Published online April 11, 2007)

Quinoline and four monofluorinated derivatives of quinoline (FQ's) were tested for their clastogenicity in a Chinese hamster lung (CHL) cell line using chromosomal aberration (CA) and micronucleus (MN) tests. Quinoline and all the fluoroquinolines, 3-, 5-, 6-, and 8-FQ, induced $\mathrm{CA}$ in the presence of the metabolic activation system. However, the clastogenic property was altered by fluorine-substitution. 3-FQ showed reduced cytotoxicity and clastogenicity. It was positive only at a higher dose than the other compounds. 6-FQ was as cytotoxic and clastogenic as quinoline when tested in the lower dose range (less than $0.075 \mathrm{mg} / \mathrm{ml}$ ). 5-FQ and 8-FQ were only moderately clastogenic in the $\mathrm{CA}$ test although their toxicity was similar to that of quinoline. The MN test showed almost the same tendency in clastogenicity as the CA test, except that 8-FQ showed a negative result. These results demonstrate that fluorinesubstitution can modify the clastogenicity of quinoline, probably through interference of the metabolic activation.

Key words_— quinoline, fluoroquinoline, chromosomal aberration, micronucleus test

\section{INTRODUCTION}

Quinoline is a hepatocarcinogen in rats and mice $^{1,2)}$ and is a mutagen in Salmonella ty-

\footnotetext{
*To whom correspondence should be addressed: Division of Cellular and Gene Therapy Products, National Institute of Health Sciences, 1-18-1 Kamiyoga, Setagaya-ku, Tokyo 1588501, Japan. Tel.: +81-3-3700-9872; Fax: +81-3-3700-9872; E-mail: suzuki@nihs.go.jp
}

phimurium TA100 in the presence of rat-liver microsomal enzymes. ${ }^{3)}$ Alterations of the genotoxic property by fluorine $(\mathrm{F})$-substitution was investigated by the Ames test. ${ }^{4-6)}$ The structures of quinoline and FQ's examined are shown in Chart 1. It was demonstrated that the mutagenicity of quinoline was severely depressed by 3-F-substitution, but not by 5-F-, 6-F-, or 8-F-substitution. ${ }^{4,5)}$ It is known that when the aromatic nucleus is substituted with an $\mathrm{F}$ atom, enzymatic oxidation is generally inhibited at the site of F-substitution. ${ }^{7-11)}$ Therefore, it was suggested that metabolic activation might have taken place in the pyridine moiety of quinoline. It was further reported that 3-fluoroquinoline (3-FQ) lacks the potency to induce both the appearance of liver placental glutathione $S$-transferase (GST-P)positive foci in rats ${ }^{12)}$ and the in vivo gene mutations in the liver of the transgenic Muta ${ }^{\mathrm{TM}}$ Mouse, ${ }^{13}$ ) whereas 5-FQ was as genotoxic as quinoline in both tests. In the present study, the clastogenic activities of four monofluorinated quinolines were tested by chromosomal aberration (CA) and micronucleus (MN) tests in vitro in order to investigate F-substitution effects on the clastogenicity, an aspect of genotoxicity, of quinoline. The relevance of the micronucleus test as an alternative to the $\mathrm{CA}$ test is also discussed in this study.

\section{MATERIALS AND METHODS}

Materials — Quinoline (CAS registry No. 9122-05) was purchased from Sigma (St. Louis, MO, U.S.A.). 3-F-, 5-F-, 6-F-, and 8-F-quinoline (CAS registry Nos. 396-31-6, 394-69-4, 396-30-5, and 396-32-7, respectively) were synthesized according to the reported methods. ${ }^{12,14,15)}$

Cells — A Chinese hamster lung fibroblast cell line (CHL/IU) was used. The cells were maintained in Eagle's minimum essential medium supplemented with $10 \%$ heat-inactivated fetal bovine serum. The modal chromosome number was 25 , and the doubling time was $15 \mathrm{hr}$.

CA Test — The CA test was performed based on the procedure reported previously. ${ }^{16-18)}$ The exponentially growing cells were treated with test chemicals for $6 \mathrm{hr}$ in the presence of rat liver S9 (final concentration 5\%, Kikkoman Co., Noda, Japan) and cofactors. After the drug-treated cells were washed, they were supplemented with fresh medium, and cultured further for $18 \mathrm{hr}$. For the 
<smiles>c1ccc2ncccc2c1</smiles><smiles>Fc1cnc2ccccc2c1</smiles>

$(3-F Q)$<smiles>Fc1cccc2ncccc12</smiles>

$(5-F Q)$

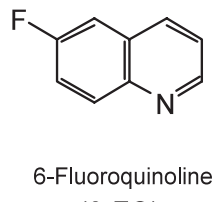

(6-FQ)<smiles>Fc1cccc2cccnc12</smiles>

(8-FQ)

Chart 1. Structures of Quinoline and Fluoroquinolines Examined

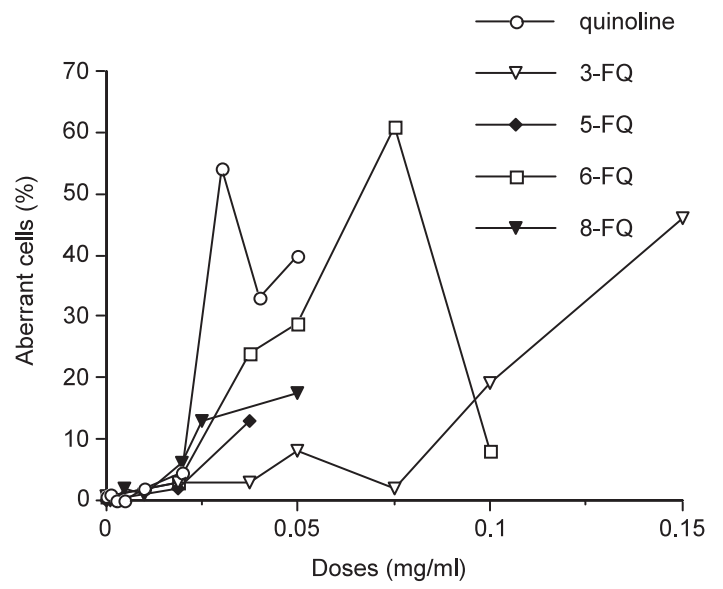

Fig. 1. Chromosome Aberration by Quinoline and Monofluorinated Quinolines in CHL Cells

Graph was obtained by summarizing data from 2-3 experiments with different dose settings.

chromosome preparation, colcemid (final concentration $0.2 \mu \mathrm{g} / \mathrm{ml}$ ) was added to the culture $2 \mathrm{hr}$ before cell-harvesting. The number of cells with CA's and the types of aberration were recorded based on the observation of 100 well spread metaphase cells per dose. Quinoline and fluoroquinolines were dissolved in dimethyl sulfoeide and $0.3 \mathrm{ml}$ each was added to $3 \mathrm{ml}$ of the culture medium. Solventtreated cells served as a negative control.

In Vitro MN Test — The cells were treated in the same manner as for the CA test and then cultured in a fresh medium for $72 \mathrm{hr}$. They were then treated with trypsin supplemented with EDTA to make a single cell suspension and incubated in $0.075 \mathrm{M}$ $\mathrm{KCl}$ hypotonic solution for $10 \mathrm{~min}$ at room temperature. The cells were fixed twice with 1:3 acetic alcohol and finally suspended in methanol containing $1 \%$ acetic acid. One drop of the cell suspension was placed on a clean glass slide and air-dried. The fixed cells were stained with $40 \mu \mathrm{g} / \mathrm{ml}$ acridine orange and immediately observed by fluorescence microscopy. The criteria for $\mathrm{MN}$ were based on the report by Matsuoka et al. ${ }^{19)}$

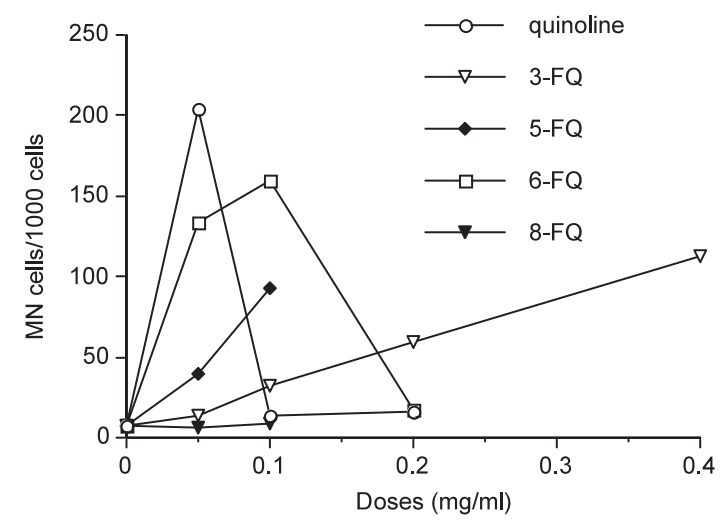

Fig. 2. In Vitro Micronucleus Induction by Quinoline and Monofluorinated Quinolines in CHL Cells

\section{RESULTS}

CA Test of Quinoline and Monofluoroquinolines

The results of the CA test on quinoline and its fluorinated derivatives are shown in Fig. 1. As previously reported, ${ }^{16)}$ quinoline significantly induced aberrant cells in CHL cells in the presence of S9 mix. Quinoline showed the highest incidence of CA at $0.03 \mathrm{mg} / \mathrm{ml}$, but seemed to be cytotoxic at higher doses, which resulted in a decrease in CA incidence. 6-FQ was also potently clastogenic to CHL cells in the presence of $\mathrm{S} 9$ mix. The number of aberrant cells induced by 6-FQ treatment increased linearly in the dose range up to $0.075 \mathrm{mg} / \mathrm{ml}$, but $0.1 \mathrm{mg} / \mathrm{kg}$ was too cytotoxic to being about the metaphase. In contrast, 5-FQ and 8-FQ were only marginally clastogenic in the lower dose range and were cytotoxic at doses higher than $0.05 \mathrm{mg} / \mathrm{ml}$. 3-FQ was less toxic than the other quinolines and only clastogenic at doses higher than $0.1 \mathrm{mg} / \mathrm{ml}$. With regard to the type of structural CA, quinoline and fluorinated quinolines induced mainly chromatid exchanges (more than $80 \%$ of aberrant cells have chromatid exchange).

\section{In Vitro MN Test of Quinoline and Monofluoro- quinolines}

As shown in Fig. 2, the results of the in vitro 
MN test of quinolines were qualitatively almost the same as those of the CA test except for 8-FQ, which was negative in the $\mathrm{MN}$ test in the dose range up to $0.1 \mathrm{mg} / \mathrm{ml}$ and cytotoxic at higher doses $(\geq$ $0.2 \mathrm{mg} / \mathrm{ml}$ ). 3-FQ linearly induced the number of micronucleated cells at doses up to $0.4 \mathrm{mg} / \mathrm{ml}$, at which all the other quinolines were cytotoxic. MN induction by quinoline was suppressed at the higher dose range because of toxicity.

\section{DISCUSSION}

As previously proposed, quinoline is converted by the rat liver microsomal enzyme system to a mutagenic metabolite, probably the 2,3-epoxide of 1,4hydrated quinoline (enamine epoxide), ${ }^{20,21)}$ which may be covalently bound to DNA bases leading to mutation in bacterial tester strains and transgenic mice. ${ }^{13,22)}$ This hypothesis was supported by the fact that quinoline was deprived of mutagenicity in vitro (in Salmonella typhimurium TA100) ${ }^{4,5)}$ and in vivo (in lacZ-transgenic mice) ${ }^{13)}$ by fluorinesubstitution at position 3 ; in the present study, a similar reduction was also observed for their clastogenicity in vitro although it was not completely diminished. F-substitution at the 3-position of quinoline inhibits epoxidation at the 2,3-position, which results in a reduction of the reactive metabolite. 3-FQ was mainly metabolized to 5,6-dihydro5,6-dihydroxy derivatives, ${ }^{23)}$ likely through hydrolysis of the corresponding 5,6-epoxides, and 5,6dihydroquinoline 5,6-epoxide was shown to be much less mutagenic than quinoline in Salmonella typhimurium TA100. 23,24) Similarly, 3FQ showed less clastogenicity and cytotoxicity than quinoline in the in vitro CA and MN tests.

On the other hand, 5-FQ was as mutagenic as quinoline in both Salmonella and transgenic mouse mutation assays ${ }^{4,5,13)}$ and it also showed a similar genotoxicity in the medium-term bioassay for hepatocarcinogenicity in rats. ${ }^{12)}$ However, in the present study, it was less clastogenic in the in vitro CA and $\mathrm{MN}$ tests. Strong cytotoxicity might cover the clastogenicity of 5-FQ or else; it is specific to the clastogenicity in vitro. Quinoline and the other mutagenic fluoroquinolines, i.e., 5-, 6-, and 8-FQ, caused CA at doses lower than $0.05 \mathrm{mg} / \mathrm{ml}$ and showed strong cytotoxicity.

These results suggest that the reactive metabolite of the pyridine moiety of quinoline, i.e., the enamine epoxide, which can be formed from quino- line and 5-, 6-, and 8-FQ, may also be clastogenic and potently cytotoxic to the cultured cells, and the less active metabolites of the benzene moiety of the quinoline, such as 5,6-epoxide which can be formed from 3-FQ, are clastogenic only in the higher dose range and are less cytotoxic.

In the present study, the MN assay gave results similar to those of the CA test, supporting its alternative use as a clastogenic test. However, 8 -FQ gave different results (weakly positive in CA but negative in $\mathrm{MN}$ assay), which suggest that the two endpoints are not exactly the same. Micronuclei can be observed only when the cells with CA pass through cell division. The predominance of the exchangetype aberration for quinolines might result in the reduction of $\mathrm{MN}$ incidence. Although a slight difference in relative sensitivity was obtained between $\mathrm{CA}$ and $\mathrm{MN}$ tests, the MN test is an easier alternative test for CA, at least qualitatively.

Acknowledgement The authors are greatly indebted to Emeritus Professor Yutaka Kawazoe, Nagoya City University, for his helpful advice and encouragement.

\section{REFERENCES}

1) Hirao, K., Shinohara, Y., Tsuda, H., Fukushima, S., Takahashi, M. and Ito, N. (1976) Carcinogenic activity of quinoline on rat liver. Cancer Res., 36, 329335.

2) Shinohara, Y., Ogiso, T., Hananouchi, M., Nakanishi, K., Yoshimura, T. and Ito, N. (1977) Effect of various factors on the induction of liver tumours in animals by quinoline. Jpn. J. Cancer Res., 68, 785-796.

3) Nagao, M., Yahagi, T., Seino, Y., Sugimura, T. and Ito, N. (1977) Mutagenicities of quinoline and its derivatives. Mutat. Res., 42, 335-342.

4) Takahashi, K., Kamiya, M., Sengoku, Y., Kohda, K. and Kawazoe, Y. (1988) Deprivation of the mutagenic property of quinoline: Inhibition of mutagenic metabolism by fluorine substitution. Chem. Pharm. Bull., 36, 4630-4633.

5) Kamiya, M., Sengoku, Y., Takahashi, K., Kohda, K. and Kawazoe, Y. (1990) Antimutagenic structure modification of quinoline: Fluorine-substitution at position-3. In Antimutagenesis and Anticarcinogenesis, vol. II, (Kuroda, Y., Shankel, D. M. and Waters, M. D., Eds.), Springer New York pp. 441-446.

6) Saeki, K., Kawai, H., Kawazoe, Y. and Hakura, A. (1997) Dual stimulatory and Inhibitory effects of 
fluorine-substitution on mutagenicity: An extension of the enamine epoxide theory for activation of the quinoline nucleus. Biol. Pharm. Bull., 20, 646-650.

7) LaVoie, E. J., Tulley-Freiler, L., Bedenko, V. and Hoffmann, D. (1983) Mutagenicity of substituted phenanthrenes in Salmonella typhinurium. Mutat. Res., 116, 91-102.

8) Hecht, S. S., LaVoie, E. J., Bedenko, V., Pingaro, L., Katayama, S., Hoffmann, D., Sardella, D. J., Boger, E. and Lehr, R. E. (1981) Reduction of tumorigenicity and of dihydrodiol formation by fluorine substitution in the angular rings of dibenzo[a,i]pyrene. Cancer Res., 41, 4341-4345.

9) Hubenman, E. and Slag, T. J. (1979) Mutagenicity and tumor-initiating activity of fluorinated derivatives of 7,12-dimethylbenz[ $a]$ anthracene. Cancer Res., 39, 411-414.

10) Diamond, L., Chain, K., Harvey, R. G. and DiGiovanni, J. (1984) Mutagenic activity of methyland fluoro-substituted derivatives of polycyclic aromatic hydrocarbons in a human hepatoma cellmediated assay. Mutat. Res., 136, 65-72.

11) Miller, E. C. and Miller, J. A. (1960) The carcinogenicity of fluoro derivatives of 10-methyl-1,2benzanthracene: 3- and 4-monofluoro derivatives. Cancer Res., 20, 133-137.

12) Saeki, K., Kadoi, M., Kawazoe, Y., Futakuchi, M., Tiwawech, D. and Shirai, T. (1997) Modification of the carcinogenic property of quinoline, a hepatocarcinogen, by fluorine atom substitution: evaluation of carcinogenicity by a medium-term assay. Biol. Pharm. Bull., 20, 40-43.

13) Miyata, Y., Saeki, K., Kawazoe, Y., Hayashi, M., Sofuni, T. and Suzuki, T. (1998) Antimutagenic structural modification of quinoline assessed by an in vivo mutagenesis assay using $l a c Z$ transgenic mice. Mutat. Res., 414, 165-169.

14) Roe, A. and Hawkins, G. F. (1949) The preparation of heterocyclic fluorine compounds by the Schiemann reaction.II: The monofluoroquinolines. J. Am. Chem. Soc., 71, 1785-1786.

15) Gerson, H., McNeil, M. W., Parmegiani, R. and Godfrey, P. K. (1972) Secondary mechanisms of antifungal action of substituted 8-quinolinols.3: 5,7,8Substituted quinolines. J. Med. Chem., 15, 105-106.

16) Matsuoka, A., Hayashi, M. and Ishidate, M. Jr. (1979) Chromosomal aberration tests on 29 chemicals combined with S9 mix in vitro. Mutat. Res., 66, 277-290.

17) Ishidate, M. Jr., Ed. (1988) Data Book of Chromo- somal Aberration Test In Vitro, Revised Edition, Elsevier/L.I.C., Amsterdam/Tokyo.

18) Matsuoka, A., Sofuni, T., Miyata, N. and Ishidate, M. Jr. (1991) Clastgenicity of 1-nitropyrene, dinitropyrene, fluorene and mononitrofluorenes in cultured Chinese hamster cells. Mutat. Res., 259, 103110.

19) Matsuoka, A., Yamazaki, N., Suzuki, T., Hayashi, M. and Sofuni, T. (1993) Evaluation of the micronucleus test using a Chinese hamster cell line as an alternative to the conventional in vitro chromosomal aberration test. Mutat. Res., 272, 223-236.

20) Tada, M., Takahashi, K. and Kawazoe, Y. (1982) Metabolites of quinoline, a hepatocarcinogen, in a subcellular microsomal system. Chem. Pharm. Bull., 30, 3834-3837.

21) Tada, M., Takahashi, K. and Kawazoe, Y. (1980) Binding of quinoline to nucleic acid in a subcellular microsomal system. Chem.-Biol. Interact., 29, 257266.

22) Suzuki, T., Miyata, Y., Saeki, K., Kawazoe, Y., Hayashi, M. and Sofuni, T. (1998) In vivo mutagenesis by the hepatocarcinogen quinoline in the lacZ transgenic mouse: Evidence for its in vivo genotoxicity. Mutat. Res., 412, 161-166.

23) Saeki, K., Takahashi, K. and Kawazoe, Y. (1993) Metabolism of mutagenicity-deprived 3fluoroquinoline: Comparison with mutagenic quinoline. Biol. Pharm. Bull., 16, 232-234.

24) Willems, M. I., Dubois, G., Boyd, D. R., Davies, R. J. H., Hamilton, L., McCullough, J. J. and van Bladeren, P. J. (1992) Comparison of the mutagenicity of quinoline and all monohydroxyquinolines with a series of arene oxide, trans-dihydrodiol, diol epoxide, $\mathrm{N}$-oxide and arene hydrate derivatives of quinoline in the Ames/Salmonella microsome test. Mutat. Res., 278, 227-236.

25) Miller, B., Potter-Locher, F., Seelbach, A., Stopper, H., Utesch, D. and Madle, S. (1998) Evaluation of the in vitro micronucleus test as an alternative to the in vitro chromosomal aberration assay: position of the GUM Working Group on the in vitro micronucleus test. Gesellschaft fur UmweltMutations-forschung. Mutat. Res., 410, 81-116.

26) Matsushima, T., Hayashi, M., Matsuoka, A., Ishidate, M. Jr., Miura, K. F., Shimizu, H., Suzuki, Y., Morimoto, K., Ogura, H., Mure, K., Koshi, K. and Sofuni, T. (1999) Validation study of the in vitro micronucleus test in a Chinese hamster lung cell line (CHL/IU). Mutagenesis, 14, 569-580. 